\title{
Lymphocyte Reproductive Activity Normalized to Numbers of Hematopoietic Stem Cells in Blood and Rate of Death in Fatal Diseases
}

\author{
Aleksei N. Shoutko ${ }^{1, *}$, Olga A. Gerasimova ${ }^{2}$, Ludmila P. Ekimova ${ }^{1}$, Fiodor Zherebtsov ${ }^{2}$, \\ Viktor F. Mus ${ }^{3}$, Kirill S. Matyurin ${ }^{1}$, Anatoly M. Granov ${ }^{2}$ \\ ${ }^{1}$ Laboratory for Improvement of the Treatment Methods, Federal Research Center for Radiology and Surgical Technologies, \\ Saint-Petersburg, Russia \\ ${ }^{2}$ Transplantation Division, Federal Research Center for Radiology and Surgical Technologies, Saint-Petersburg, Russia \\ ${ }^{3}$ Group for Lung Cancer Treatment, Federal Research Center for Radiology and Surgical Technologies, Saint-Petersburg, Russia
}

\section{Email address:}

shoutko@inbox.ru (A. N. Shoutko)

${ }^{*}$ Corresponding author

\section{To cite this article:}

Aleksei N. Shoutko, Olga A. Gerasimova, Ludmila P. Ekimova, Fiodor Zherebtsov, Viktor F. Mus, Kirill S. Matyurin, Anatoly M. Granov. Lymphocyte Reproductive Activity Normalized to Numbers of Hematopoietic Stem Cells in Blood and Rate of Death in Fatal Diseases. International Journal of Genetics and Genomics. Vol. 5, No. 5, 2017, pp. 54-62. doi: 10.11648/j.ijgg.20170505.12

Received: January 29, 2017; Accepted: February 13, 2017; Published: October 18, 2017

\begin{abstract}
The numbers of $\mathrm{CD} 133^{+}$and $\mathrm{CD} 31^{+}$lymphocytes and those in the $\mathrm{G} 2-\mathrm{M}$ phases in the total fraction of circulating lymphocytes from patients with fatal liver cirrhosis and advanced lung cancer were investigated by flow cytometry during a long period of conventional treatment with OLT or palliative surgery followed by myelosuppressive chemotherapy. The relationships of specific reproductive activity, sRA $\left(\mathrm{G} 2-\mathrm{M} / \mathrm{CD} 133^{+}\right)$, and the number of committed liver $\alpha$-fetoprotein-positive $\left(\mathrm{AFP}^{+}\right)$cells with the rate of patient deaths, characterized by exponential approximation survival curves for both diseases, were investigated. Subnormal sRA in patients after OLT and excessive sRA in LC patients above a healthy level were associated with higher death rates and lower survival, coinciding with strong immunosuppression caused by anti-rejection and anti-cancer therapies. These findings may be explained by morphogenesis (feeding) activity of circulating lymphocytes targeted toward both normal and malignant tissues rather than in terms of cellular immunity. The sRA changes may be a useful indicator for monitoring the potential for engraftment or tumor growth.
\end{abstract}

Keywords: Hematopoietic Stem Cells, Lymphocytes, Specific Reproductive Activity, Resource of Lymphopoiesis, Lung Cancer Therapy, Liver Transplantation, Death Rate

\section{Introduction}

Strongly proliferating $\mathrm{CD} 133^{+}$progenitor cells of bone marrow (BM) origin may differentiate into cells with characteristics of mesoderm, endoderm, and neuroderm layers, such as endothelial progenitor cells, neural progenitor-like cells, astrocytes, oligodendrocytes, kidney proximal tubule cells, lactiferous duct cells of the mammary gland, prostate gland cells, skin cells, lung cells, intestinal cells, skeletal muscle-like cells, and hepatocyte-like cells. Circulating $\mathrm{CD}_{133^{+}}$hematopoietic stem cells (HSCs) can be committed to tissues of different types and support regenerative processes in them $[1,2,3]$. These $\mathrm{CD} 34^{+}$ progenitor cells can accelerate the aggressiveness of the malignant process [4]. The $\mathrm{CD}^{+} 1^{+}$lymphocytes (Lph) in peripheral blood $(\mathrm{PB})$ are more mature descendants of $\mathrm{CD}_{133^{+}}$progenitors; they both are able to take part in vasculogenesis, and have tumor-propagating capacities [5].

It is not sufficient to determine only the numbers of HSCs $\left(\mathrm{CD} 133^{+}\right.$and $\left.\mathrm{CD} 34^{+}\right)$or their descendants in peripheral blood to predict long-term biological activity in lymphocytopoiesis. The current proliferative potency of progenitors and descendants is also important. Hayflick's limit characterizes the maximum number of divisions that a single cell is able to undergo, despite telomerase activity, 
until its death. The ability of an organism to reproduce cells becomes weaker with age and with some diseases [6, 7], especially those with life-threatening pathologies [8, 9]. The decrease in human life span (LS) with age is accompanied by a reduction in lymphocytopoietic activity in organisms, a marked decline in the production of naïve $\mathrm{T}$ cells, and an increase in granulocyte numbers $[7,10]$. As the mitotic phase of renewal in the lymphocytic compartment of $\mathrm{PB}$ is a valuable measure of current proliferative capacity, we considered that dividing mitotic activity of the lymphoid cells in $\mathrm{PB}$ by the number of circulating CD133 ${ }^{+} \mathrm{HSCs}$ (specific reproductive activity, sRA) might provide a more reliable measure of the long-term functional potential for lymphocytopoiesis. Thus, we assessed the relationship between specific mitotic reproductive activity, sRA, and instantaneous death rate (DR) in two groups of patients with fatal diseases: liver cirrhosis, treated by orthotropic liver transplantation (OLT), and lung cancer after palliative surgery, both followed by conventional cytotoxic therapy. The ability of $\mathrm{CD} 133^{+}$cells to provide renewal of different tissues and thus support the viability of the organism overall was checked by determining the number of circulating Lph committed to liver tissue ( $\alpha$-fetoprotein-positive, $\mathrm{AFP}^{+}$) along with evolution of sRA and DR values over several years following the start of conventional therapy.

\section{Methods}

\subsection{Patients}

The subjects, 95 adult patients with orthotropic liver transplantation (OLT) and 43 with advanced non-small cell lung bronchioloalveolar carcinoma (LC), received conventional therapy at the Russian Research Center of Radiology and Surgical Technologies (RRCRST) in St. Petersburg, as described previously [4, 11]. OLT was followed by chemotherapy with basiliximab and immunosuppressive treatment, including tacrolimus and mycophenolate with prednisone. LC patients received conventional chemoradiotherapy after palliative surgery.

The cumulative 3-year survival rate of patients with OLT, measured by the Kaplan-Meier method, was $82 \%$. The cumulative 1- and 3-year survival rates of patients with LC were $26 \%$ and $7 \%$, respectively.

The institutional ethics committee approved this study. Informed consent was obtained from all patients.

\subsection{Death Rates}

Survival curves for each subgroup were approximated using exponential curve fitting in Excel [12], with the following equation:

$$
\mathrm{S}_{\mathrm{t}}=\mathrm{A} \mathrm{e}^{-\mathrm{kt}}+\mathrm{B} \mathrm{e}^{-\lambda \mathrm{t}}+\mathrm{C}
$$

where $S_{t}$ is the proportion of surviving patients at any point during the 5-year period, $t$ is the time (months) after the beginning of therapy, $\mathrm{k}$ and $\lambda$ are the exponential death rates per month (DR), and A and B are the proportions of patients who died correspondingly with monthly DR $\mathrm{k}$ or $\lambda$. C is the proportion of those who had not died during the extended 5year follow-up period.

\subsection{Blood Samples for Flow Cytometry}

A parallel randomized study of blood samples was conducted within 108 months after the beginning of therapy, with written informed consent, in 21 OLT patients (average age $39.9 \pm 12.1$ years, nine females, twelve males) and $13 \mathrm{LC}$ patients (average age $44 \pm 9.2$ years, six females, seven males). A separate group of six healthy adult volunteers (average age 55 years, three females, three males) was used to provide control (baseline) data.

Blood samples $(10 \mathrm{~mL})$ were first taken before OLT or LC treatment. Then, samples were taken repeatedly at convenient times from those who were alive during three consecutive periods after the therapy started, but who died later. The corresponding periods after the start of treatment were $>0$ $\leq 7,>7 \leq 44$, and $>44 \leq 108$ months. Immediately after PB was collected from a patient, the mononuclear cell fraction (MNC) was isolated by classical Ficoll density separation [13], omitting the final step of magnetic cell enrichment. Viability was assessed with the trypan blue exclusion test. Cells from two equal parts of the fresh MNC fraction were stained for flow-cytometry analyses.

The nucleic acid stain Hoechst33342 (bisbenzyimidazole fluorochrome; Sigma) was used for cell-cycle analysis, which was performed according to [14], with slight modifications. First, MNCs were resuspended at a density of $10^{6}$ cells $/ \mathrm{mL}$ in pre-warmed $\left(37^{\circ} \mathrm{C}\right) \mathrm{DMEM}+2 \%$ heat-inactivated fetal calf serum (FCS; Gibco BRL, Grand Island, NY, USA) and 10 mM HEPES (Gibco BRL). Hoechst33342 was added to a final concentration of $5 \mu \mathrm{g} / \mathrm{mL}$, and the cells were placed in a $37^{\circ} \mathrm{C}$ water bath for $120 \mathrm{~min}$. Tubes were mixed gently every $20 \mathrm{~min}$ during the incubation. Then, cells were centrifuged (483 relative centrifugal force, $\mathrm{RCF}$, for $6 \mathrm{~min}$ at $4^{\circ} \mathrm{C}$ in a precooled rotor), resuspended in cold HBSS / 2\% FCS / 10 $\mathrm{mM}$ HEPES at a concentration of $1-2 \times 10^{7}$ cells $/ \mathrm{mL}$, and kept at $4^{\circ} \mathrm{C}$ until analysis.

The phenotypes of the circulating cells in the lymphoid part of the MNCs were evaluated using standard protocols for cell staining. MNCs were prepared for conventional dual-color immunophenotyping with fluorescence of allophycocyanin (APC)-directly conjugated anti-CD133/2 monoclonal antibodies (MoAbs), fluorescein isothiocyanate (FITC)directly conjugated anti-CD31 MoAbs, and phycoerythrin (PE)-directly conjugated anti-AFP ( $\alpha$-fetoprotein) MoAbs. The APC-conjugated MoAbs were from Miltenyi Biotec (Bergisch Gladbach, Germany), the FITC-conjugated MoAbs were from BD Bioscience Pharmingen (San Jose, CA, USA), and the PEconjugated MoAbs were from R\&D Systems (Minneapolis, $\mathrm{MN}$, USA). Isotype-matched irrelevant MoAbs (BectonDickinson) were used as negative controls.

\subsection{Flow Cytometry}

An LSR Fortessa flow cytometer (Becton-Dickinson, San 
Jose, CA, USA) was adjusted for immunofluorescent before each measurement using the BD Cytometer Setup and Tracking Beads kits. The Lph and monocytes (Mn) fractions were separated by gating on forward (FSC) and side (SSC) light scatter dot plots, excluding cellular debris. A red laser $(640 \mathrm{~nm}, 40 \mathrm{~mW})$ was used for the detection of CD133 cells, a blue laser $(480 \mathrm{~nm}, 50 \mathrm{~mW})$ for detection of $\mathrm{AFP}^{+}$ and $\mathrm{CD} 31^{+}$cells, and a UV laser $(355 \mathrm{~nm}, 20 \mathrm{~mW})$ for cells labeled with Hoehst33342.

\subsection{Flow Cytometry Analysis}

The proportion $(\%)$ of AFP-positive cells $\left(\mathrm{AFP}^{+} \mathrm{CD} 31^{+}\right.$ subset) in the $\mathrm{CD} 31^{+}$fraction of the Lph pool was calculated as described in [3]. A dot-plot of double (simultaneous) emission of Hoehst33342 in blue ( $x$-axis) and red ( $y$-axis) wavelengths was used for the separation of events, G0-G1, S, and G2-M phases, according to [13, 14]. The major double-negative emitting population (blue and red) in lower left corner of the plot represents cells in the $\mathrm{G}_{0}-\mathrm{G}_{1}$ phase of the cell cycle. The center and upper right corner of the dot plot shows the doubleemitting cells in the $\mathrm{S}$ and $\mathrm{G}_{2}+\mathrm{M}$ phases of the cell cycle. Then, data from the Hoechst33342 red versus blue bivariate plot were used to calculate the specific reproductive activity (sRA) for each patient: (percentage of $\mathrm{G}_{2}-\mathrm{M}$ phase events / percentage of CD 133-positive cells in the pool of Lph). A minimum of 500,000 total events was recorded twice when $\mathrm{AFP}^{+} 133^{+}$cells were investigated in the Lph fraction. The percentage of positive cells was calculated by subtracting the value of the appropriate isotype control.

\subsection{Kinetic and Statistical Analyses}

The goal was to find changes in signs over time since the start of treatment. Time-related curve fitting was performed using Microsoft Excel software [15]. We defined the functions that best described the trends in the data using equations. For kinetic analyses of survival curves according to these formulae (1), exponential regression lines were determined.

The $\mathrm{G}_{2}-\mathrm{M}, \mathrm{CD}_{133^{+}}$, and sRA values were averaged in frames of three time periods after treatment $(>0 \leq 7,>7 \leq 44$, and $>44 \leq 108$ months) for each group, OLT, and LC, and these were compared by kinetic analyses. The relationships of residues of sRA in each of the three kinetic intervals ( $\Delta$ sRA) with corresponding data of those who died ( $\Delta$ of death) and with $\mathrm{k}$ - or $\lambda$-values in the corresponding time interval were then assessed.

To determine a line that adequately described the non-linear trends, we used higher order polynomial approximations. As the coefficient determination $\mathrm{R}^{2}$ is a statistical measure of the goodness of fit of the regression line to the data, we assessed its maximal value. Confirmation of satisfactory $\mathrm{R}^{2}$ values was made according to equation (2) [16]:

$$
t=\sqrt{ }\left[R^{2}(n-2) /\left(1-R^{2}\right)\right]
$$

Student's t-test, standard error (SE), and probability (p) were used for comparing the mean values (M), as necessary. A p-value $\leq 0.05$ was considered to indicate statistical significance.

\section{Results}

\subsection{Viability of Patients}

The graphical analysis of survival in a semi-logarithmic plot is shown in Figure 1.

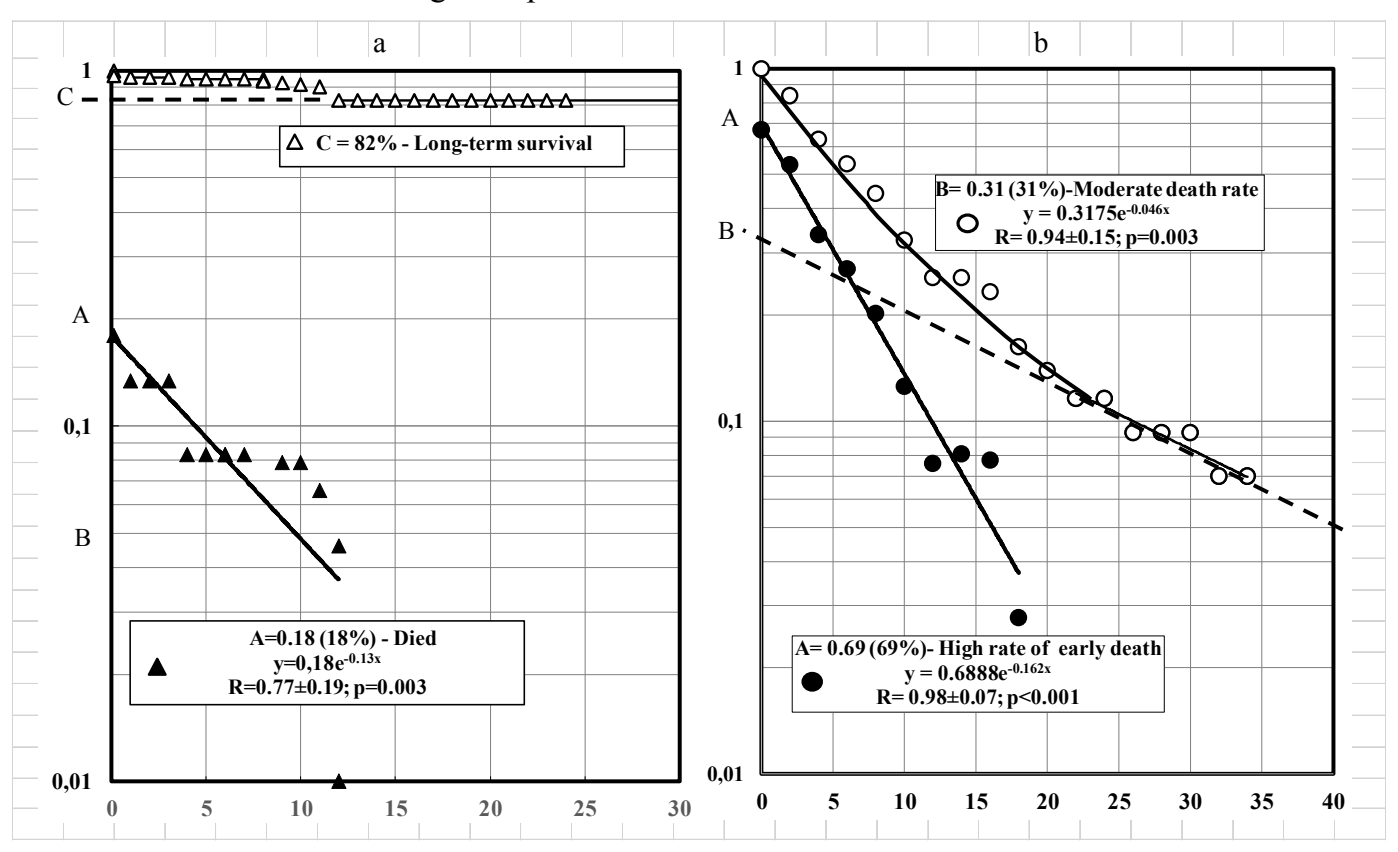

Figure 1. Survival of patients with OLT (a) and LC with conventional therapy (b). 
the survivors, C. b) LC; white circles, common curve; black circles, (A) proportion who died with high DR k; (B) proportion who died with slow DR $\lambda$.

A small proportion, A, of patients with OLT (18\%) died at around 1 year, and the rest (82\%) were alive at 60 months (constant part, C). Most of the patients with LC had died within 1 year $(69 \%$, A), and only 31\% died more slowly, up to 5 years after treatment. The parameters of the equations for the exponential approximations shown in Figure 1 are given in Table 1.

Table 1. Parameters of exponents approximated from survival curves.

\begin{tabular}{|c|c|c|c|c|c|c|c|}
\hline Proportions $(A, B, C)$ and DR $(k, \lambda)$ for Exponents on Figure 1 & $\mathbf{A}$ & $\mathbf{k}$ & B & $\lambda$ & $\mathbf{R} \pm \mathbf{S E}$ & $\mathbf{p}$ & $\mathbf{C}$ \\
\hline a) Liver transplantation, triangles & 0.18 & 0.13 & 0 & 0 & $0.775 \pm 0.19$ & 0.003 & 0.82 \\
\hline b) Lung cancer treatment, circles & 0.69 & 0.17 & 0.31 & 0.0046 & $\begin{array}{l}0.98 \pm 0.07 \text { for } \mathrm{k} \\
0.94 \pm 0.15 \text { for } \lambda\end{array}$ & $\begin{array}{l}<0.001 \\
0.003\end{array}$ & 0 \\
\hline
\end{tabular}

Three 'types' of survival were selected for further investigation of circulating cells: two with relatively high death rates, DR $\left(\mathrm{k}=0.13\right.$ month $^{-1}$ or $\left.\mathrm{k}=0.17 \mathrm{month}^{-1}\right)$ for group A of patients with OLT and LC, and the other with slow DR $\left(\lambda=0.046\right.$ month $\left.^{-1}\right)$ for proportion $B$ of patients with LC and no death (DR $=0$; portion $\mathrm{C}=82 \%$ for OLT).

\subsection{Monitoring of $G_{2}-M$ and $C D 133^{+}$Cells in Blood}

The data below were used to compare survival parameters. Figure $2 \mathrm{a}$ and $2 \mathrm{~b}$ show the kinetics of the averaged percentage of CD133-positive Lph, the percentage of $\mathrm{Lph}$ in $\mathrm{G}_{2}-\mathrm{M}$ phases, and the averaged specific reproductive activity (sRA), expressed as a percentage of $\mathrm{G}_{2}-\mathrm{M}$ phase events divided by the percentage of CD 133-positive cells in the Lph pool.

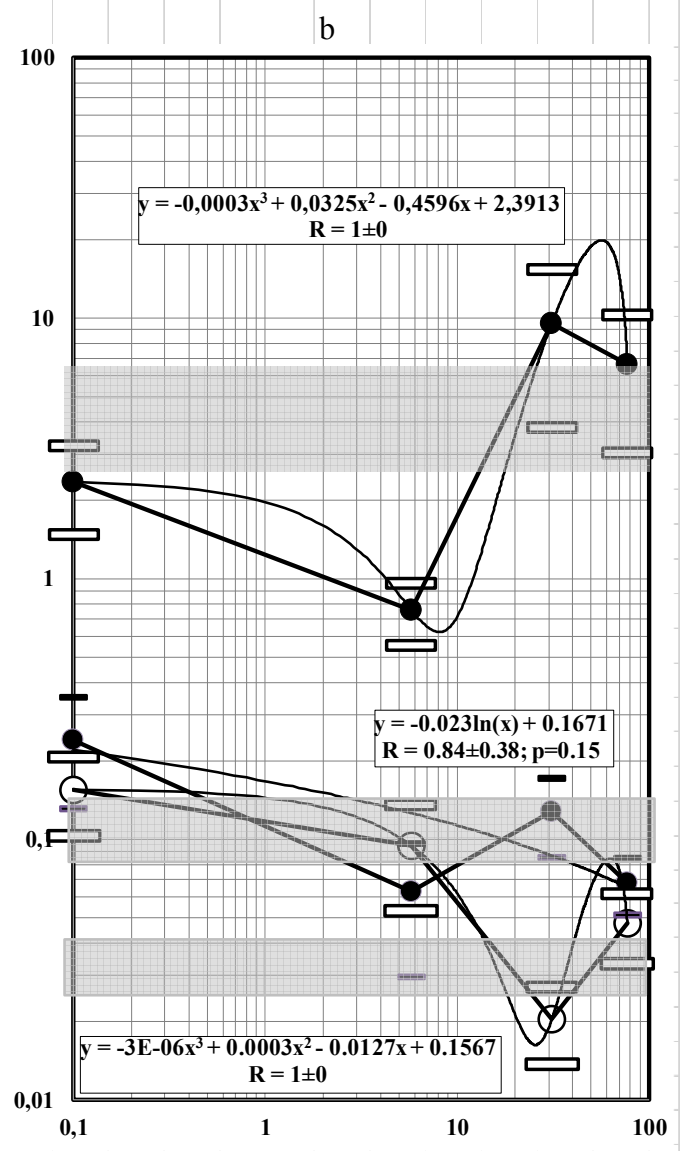

Equations for the thin approximated lines are shown in boxes. Gray zones: control $\mathrm{M} \pm \mathrm{m}$ for healthy donors: lower CD133+, middle G2-M, and upper sRA.

Figure 2. Kinetics of CD133 ${ }^{+}$Lph (white), G G $_{2}$ M phases of Lph (black, lower), and SRA (black, upper) for LC (a) and OLT (b) patients.

Comparing the data for OLT and LC patients in Figure 2a and $2 \mathrm{~b}$ reveals three main differences between them. First, the percentage of $\mathrm{CD} 133^{+} \mathrm{Lph}$ was lower and the percentage of $\mathrm{G}_{2}-\mathrm{M}$ phase cells higher in LC compared with OLT patients. Second, the specific reproductive activity (sRA) in LC was several times higher than that in OLT over the whole time period. Third, the final sRA value for long-living OLT patients was the same as the control level for healthy donors, 
preliminarily evaluated as $4.2 \pm 2.1$. In contrast, the final sRA value for part B LC patients exceeded this reference level significantly (four fold). To understand more precisely the functional role of sRA deviations, their residues, $\Delta$, in the elapsed periods of time (according to Fig. 2a and b) were related to corresponding residues, $\Delta$, of survival A (according to Figs. 1 $\mathrm{a}$ and $\mathrm{b}$ ) and the exponential DRs, $\mathrm{k}$ and $\lambda$ (from Table 1). The interconnections are presented in Figure 3, where data for the two pathologies are combined as the total dependency.

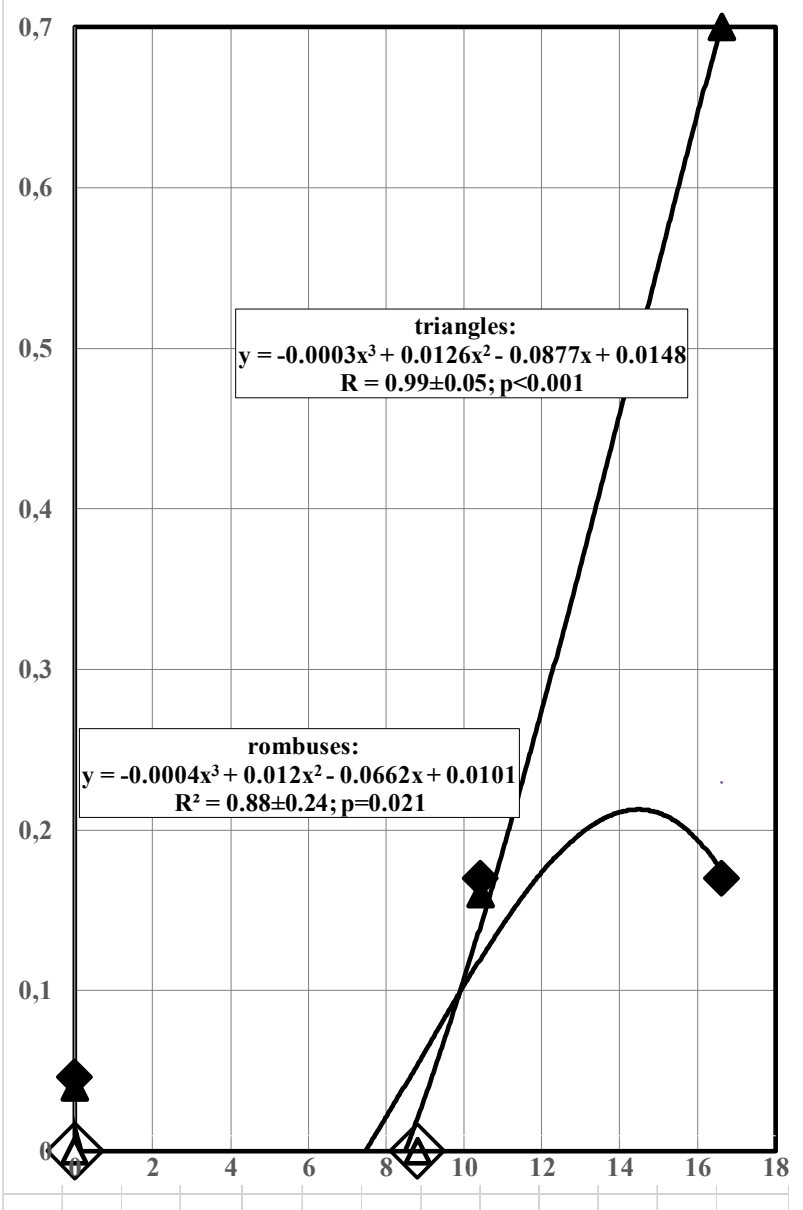

Figure 3. Changes $(\Delta)$ in survival (y-axis, triangles) and exponential DR (yaxis, rhombuses) with residues $(\Delta)$ of $s R A$ (x-axis).

Black, LC; white, OLT. Formulae of the approximated lines are shown in boxes: upper for $\mathrm{y}=\Delta$ survival, lower for $\mathrm{y}=\mathrm{DR}$.

During several months after beginning treatment, the deviation of sRA to the left (negative values on the $x$-axis, Fig. 3) or to the right (positive values $\geq 8$ on the $x$-axis, Fig. 3) showed a significant loss in the number of patients in both OLT and LC. The deviation of SRA in the opposite direction from its normal level resulted in an increasing DR.

In the OLT group during the following time interval after 10-12 months, sRA returned to a normal ('healthy') level, at which death did not occur up to 3 years post-treatment (constant survival, $\mathrm{B}=82 \%$ ). This confirmed the important of keeping the sRA around the normal value for successful long-term therapy in OLT.

Exceeding the normal level, as happened among LC patients during the first and second time intervals, was associated with the deaths of $16 \%$ and $70 \%$ of patients, respectively. Later ( $\geq 3-5$ years), when the sRA residues $(\Delta)$ became zero (LC) or even negative (OLT), minimal DR values and numbers of deaths were seen (Fig. 3).

\subsection{Monitoring of Blood AFP ${ }^{+}$Lph Committed to the Liver}

An increase in $\mathrm{AFP}^{+} \mathrm{CD} 31^{+}$cells in the $\mathrm{CD} 31^{+} \mathrm{Lph}$ fraction of the blood was seen several months after OLT (Fig. 4).

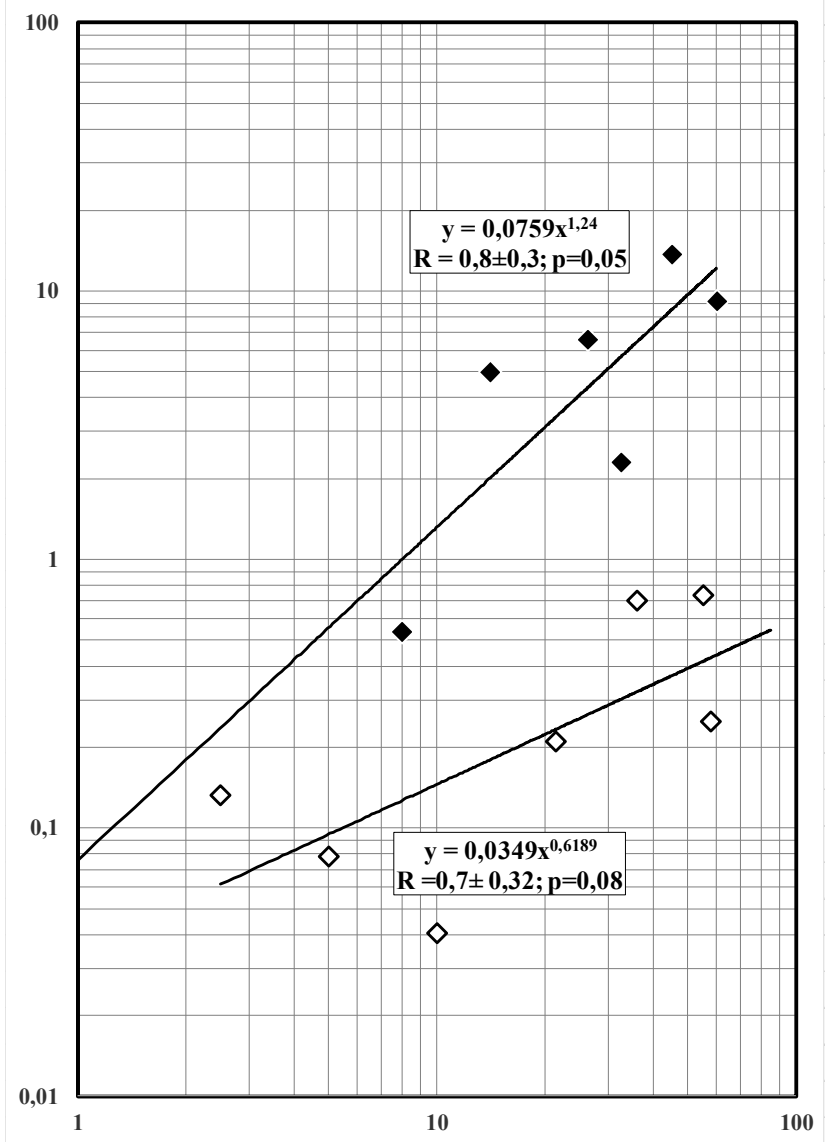

Figure 4. $A F P^{+} C D 31^{+}$Lph content in $P B(y)$ from time elapsed since the start of therapy $(x)$.

Black, OLT; white, LC. Formulae of the approximated lines are shown in boxes: upper for OLT, lower for LC.

This continued up to 60 months after transplantation, coinciding with normalization (increasing) of sRA values after the initial decrease and cessation of deaths among liver recipients. In contrast, no statistically significant increase in $\mathrm{AFP}^{+} \mathrm{CD} 31^{+}$cells in the $\mathrm{CD} 31^{+}$fraction was found for the LC group during the similar time period. The data in Figure 4 show the commitment of some of CD $31^{+}$Lph to the transplant at $\geq 8$ months after OLT, which may point to their positive role in the adaptation of the new organ to the new host. 


\section{Discussion}

\subsection{OLT}

The early death of a considerable proportion of the liver recipients $(\mathrm{A}, 18 \%)$ at a high rate $\left(\mathrm{k}=0.13 \mathrm{month}^{-1}\right)($ Fig. 1) was associated with parameters close to those reported in [17] for a low-risk group of OLT patients $(\mathrm{A}=12 \%$ and $\mathrm{k}=$ 0.13 month $\left.^{-1}\right)$. The deaths might be explained by the drop in sRA and the lack of trophic properties of the lymphocytes caused by strong anti-rejection therapy during the first $5-10$ months post-OLT (Fig. 3, left descending branch). This temporary period coincides with serious issues in engraftment, which include regeneration of the vascular net of the graft and its short-term adaptation to the feeding system of the host. Indeed, the regeneration of the transplanted liver is especially important in the first weeks after the surgical reconstruction of its blood supply [18]. Poor early survival in older liver recipients versus younger ones results from the weak regenerative capacity of the relatively frail host $[19,20]$. Generally, stem cell therapy, even with autologous $\mathrm{CD}_{133^{+}}$cells, has been found to enhance angiogenesis and functional recovery in clinical trials for patients with chronic total occlusion and ischemia, myocardial infarction, hepatic fibrosis, liver, and bone regeneration [21]. Up to $50 \%$ of intrahepatic lymphocytes are immature, and reduction in their numbers coincides with an increase in the risk of "autoimmune frustration," or a decrease in the so-called tolerogenicity of the organ [22]. From that perspective, the initial strong immunosuppressive therapy seems to be paid for in the suppression of sRA, which has to supply liver function by circulating BM cells committed to the new liver tissue, i.e., the natural mechanism of the new organ's adaptation.

As soon as the anti-rejection therapy is moderated, sRA values increase, as does the percentage of $\mathrm{AFP}^{+} \mathrm{CD} 31^{+}$cells committed to the transplant tissue (Figs. 2b, 3, 4). The restoration of both parameters has long-term effects, coinciding with lack of deaths during the period from 10-12 months up to 60 months. The sRA increase does not exceed the average level for healthy donors, but does provide an increase in $\mathrm{CD}_{3} 1^{+} \mathrm{AFP}^{+}$lymphocytes specific to the grafted tissue. The specificity of enhancement is obvious because it is much higher than that in non-specific cases associated with physiological stress after surgery and subsequent long-term cytotoxic therapy in LC patients (Fig. 4). The data of [3] and those shown in Figure 4 indicate that over the long term, the transplant per se is a strong and specific stimulus for the normalization of the sRA level, together with mobilization of $\mathrm{AFP}^{+}$liver-committed cells in the blood. The long period of increasing $\mathrm{AFP}^{+}$committed cells under conditions of mild immunosuppression shows that adaptation of the transplant to the host may continue for many years in those who survive the immediate period after the operation (B, 82\%). Nevertheless, slight decreases in both the number of circulating $\mathrm{CD} 133^{+} \mathrm{Lph}$ and the common mitotic activity of the descendant cells compared with healthy donors are seen during the years of continuing mild immunosuppression (Fig.
$2 \mathrm{~b}$ ). Thus, the data in Figure 3 (where $\Delta \mathrm{sRA} \approx 0-8$ ) may be interpreted as an increase in the viability of the engraft with recovery of the sRA value and the specificity of morphogenic $\mathrm{CD} 31^{+}$Lph to the new tissue. We suggest that the process of adaptation of the orthotopically transplanted organ in the host includes, at minimum, a long collaboration with the lymphocytopoietic branch of hematopoiesis.

Endothelial cell adhesion molecule (CD31) is important in the process of leukocyte transmigration through intercellular junctions of vascular endothelial cells and in supporting the capacity of lymphocytes to move into and through extralymphoid tissue. The phenotypic profile of the youngest resident hepatic stem cells (HepSCs) does not include AFP or any marker for hematopoietic (CD34 and CD45) or endothelial (VEGFr and CD31) tissues, apart from the CD133 molecule [23]. That is why they are hardly a target for $\mathrm{AFP}^{+} \mathrm{CD} 31^{+}$cells. Immature unipotent hepatoblasts, which expand during regenerative processes in the liver, have an antigenic profile, with strongly positive expression of both CD133 and the hepatic-specific AFP marker, but they lack the CD31 marker [24, 25]. Thus, they are likely to target $\mathrm{CD}_{133^{+}} \mathrm{AFP}^{+}$-committed migrants [3] or CD133 ${ }^{+}$VEGFR2 ${ }^{+}$ angiogenic cells [26]. The AFP-homing of committed CD31 ${ }^{+}$ lymphocytes may be more related to resident progenitor hepatic cells because only they are AFP positive [27]. Circulating blood $\mathrm{CD}_{3} 1^{+} \mathrm{T}$ lymphocytes also have vasculogenic potency [28]. AFP, which is delivered by $\mathrm{CD} 31^{+} \mathrm{AFP}^{+}$and/or $\mathrm{CD}_{133^{+}} \mathrm{AFP}^{+}$cells, may stimulate angiogenesis in target tissues [25, 27]. Silencing of AFP expression reduces hepatic VEGF expression significantly [29].

Unfortunately, collaboration in the BM-graft axis in the earliest period is subject to conflict created by strong immunosuppressive therapy between anti-rejection gain and bodily harm. According to the data in Figures 1a, 2b, and 3, OLT is typically successful for only those cases (C, 82\%) where the sRA parameter has recovered at least to the normal (healthy) level after its earlier substantial decrease. Taken together, these data indicate the value of a normal mitotic regime in the lymphopoietic branch for somatic prosperity and life. We found no argument for any waste of the reproductive potency of lympocytopoiesis in long-lived patients, as they do not show sRA values in excess of normal. The data largely confirm the harmfulness of artificial sRA reduction for viability in OLT patients, as well as in others with a non-malignant regeneration pathology. Nevertheless, the relatively short orthotopic liver graft survival $(\approx 17.8$ years) in $\approx 57$-year-old recipients [16] may reflect a deficit rather than natural longevity, as the average remaining life expectancies for Americans who reach the age of 75 (i.e., 57 +17.8 ) are 11 and 12.2 years for men and women, respectively [30]. This supposed deficit in life span for recipients might be a result of long-term immunosuppressive treatment [31].

\section{2. $L C$}

Our results show that treated LC patients live nearly as 
long as those reported by the Surveillance, Epidemiology and End Results (SEER) database of the National Cancer Institute for treated bronchioloalveolar carcinoma: $28 \%$, in the United States; 1-year survival, $29.1 \%$ and 5-year survival, $4.4 \%$ [32]. Thus, the treatment's benefit coexist with the abnormally high sRA and the high death rate (DR, 0.17 month $^{-1}$ ) of more than $2 / 3$ of all patients (Table $1, A=69 \%$; Fig. 1b). Such fatalities due to the overtaxing of $\mathrm{Lph}$ reproduction are not explained by speculation about enhancing immune defenses during the repopulation of circulating Lph after conventional myelosuppressive therapy [33]. Anti-tumor immune enhancement also does not explain the reduction in DR (from $\mathrm{k}=0.17$ to $\lambda=0.046$ ) when the positive vector $\Delta$ of the sRA-dynamic becomes zero between 18.7 and 43.3 months in LC therapy (Fig. 3). Overcompensated sRA among descendant cells is a result of a deficit in circulating $\mathrm{CD}_{133^{+}} \mathrm{Lph}$ (Fig. 2a), and points instead to the ability of young Lph to potentiate proliferation in different tissues, including malignant ones [3]. The 2-9fold "reproductive supertension" of $\mathrm{CD} 133^{+}$progenitors (sRA) relative to the healthy level, together with a high DR $(\mathrm{k}=0.17)$, may be more explicable if the young Lph support the proliferation of not only normal but also malignant cells. This seems realistic because, although on the one hand, myelosuppression (Fig. 2a) is inseparable from the benefit of cancer therapy [34, 35, 36, 37], on the other hand, it is related to the life-threatening complication of conventional cytotoxic chemoradiotherapy, especially for patients with already exhausted hematopoietic resources as a result of HSC numbers and Hayflick's limit.

The shortage of hematopoietic resources in a fatal LC case may be caused by accelerated gradual wasting long before the start of treatment. In this view, there is a (more than three-fold) decrease in the frequency of lymphoid progenitor cells with age, accounting for lymphoid deficiency in elderly individuals [38]. Thus, the strong and long-term reduction in the percentage of $\mathrm{CD}_{133^{+}}$Lph with age and beyond that in malignant patients (Fig. 2a vs. Fig. 2b), can be considered a direct consequence of the accelerated aging of the body of the LC host.

At the same time, artificial hematodepression induced by cytotoxic therapy in cases of malignant disease may be a two-edged sword. It beneficially limits a trophic BMmalignant tissue axis, but it ultimately restricts the axis with normal tissues of the host, too. The naturally and slightly depleted production of young lymphocytes during thymus involution with age is accompanied by temporary retardation of the cancer death rate in human populations [9]. In this way, moderate post-treatment lymphocytopenia may contribute to the common benefits of cytotoxic therapy. However, depending on the initial (basal) capacity for poiesis in an individual patient, it may be deadly [34, 37, 39, 40]. Earlier, based on a dog population irradiated throughout life with low daily doses, which are harmful to the productive function of the $\mathrm{BM}$, we argued that the lower the capacity of BM to provide proliferation in normal tissues is, the shorter the life span will be and the fewer newly registered solid malignancies will occur [41].
One reason for early somatic frailty incompatible with life in cancer patients (i.e., cachexia) seems to be the privilege of quasi-embryonic malignant tissues to use morphogenic cells from BM for their own cellular renewal, even in the absence of cytotoxic treatment. The abnormal increase in sRA (Fig. 2a) may be a universal insurance mechanism, an attempt to support the number of morphogenic Lph in circulation during an emergency, by analogy to telomerase at a molecular level. This mechanism in LC rather points to the inability of the therapy to suppress cancer promotion by young Lph, even if a substantial reduction in the number of $\mathrm{CD} 133^{+}$progenitors is apparent. Thus, a supernormal sRA value in malignant disease might be interpreted as a predictor of lifespan reduction due to the enormous waste of morphogenic potency aimed at providing physiological longevity, which is naturally limited. Beyond this, a supernormal sRA value may be a measure of resistance to cytotoxic / myelosuppressive therapy.

The damage caused by deficit of morphogenic potency seems to have a biological characteristic in that it can be traced to biomass reproduction in the human fetus. Early life reproduction and more births are associated with increased mortality risk and reduced survival in humans [42, 43]. The normally uncomplicated second and third trimesters of human pregnancy are accompanied by strong natural overproduction of double-positive $\mathrm{CD}_{3} 4^{+} \mathrm{VEGFR}^{+}$and $\mathrm{CD}_{133^{+}} \mathrm{VEGFR}^{+}$ blood cells. A decline in the numbers of these cells in the third trimester has been associated with preeclampsia [44]. Preeclampsia leads to substantial widespread endothelial damage, and is a leading cause of pregnancy-related death. The only definitive treatment for preeclampsia is termination of the pregnancy and delivery of the fetus and placenta. [43]. By analogy, the quasi-embryonic nature of malignant tissues makes them privileged and preferred targets for circulating morphogenic cells, reproduction of which in the BM may be accelerated and then rapidly and completely exhausted during times of disease that are much longer than the 9 months of the natural limit for the accelerated biomass gain in pregnancy. Taken together, the data in Figure 3 reflect the duality of the sRA parameter for viability, as it depends on domination of one of two threats to life: a deficit in morphogenic activity in OLT or an excess in malignant growth. This hypothesis seems the best way to explain the results obtained.

\section{Conclusions}

Long-term enhancement of the specific reproductive activity (sRA) of $\mathrm{CD}_{133^{+}}$progenitor Lph has opposite effects on lifespan in treated patients with OLT or LC. Subnormal sRA in patients after OLT and excessive sRA in LC patients, compared with a healthy level, were associated in both with high death rates and low survival, coinciding with strong immunosuppression due to anti-rejection and anti-cancer therapies. The findings here may be more easily explained by the morphogenic activity of circulating lymphocytes, targeted toward both normal and malignant tissues, than in terms of cellular immunity. sRA changes may be a useful indicator for monitoring the potential for engraftment or tumor growth. 
The English in this document has been checked by at least two professional editors, both native speakers of English. For a certificate, please see:

http://www.textcheck.com/certificate/MaPFnd

\section{Acknowledgements}

There were no special funds or grants, except regular financing of research by the Ministry of Health Care to which the Center is affiliated.

\section{References}

[1] M. Kucia, J. Ratajczak, and MZ. Ratajczak, Bone marrow as a source of circulating CXCR4+tissue- committed stem cells, Biol Cell, vol. 97 (2), pp. 133-146, February 2005. doi:10.1042/BC20040069.

[2] Ch. Drapeau, Cracking the stem cell code: demystifying the most dramatic scientific breakthrough of our times. Hillsboro, Or, Goodwill Books USA, Sutton Hart Press $/ 1^{\text {st }}$ ed. 2010. http://www.amazon.com/Cracing-Stem-Cell-CodeMiraculous/dp/098102095X.

[3] A. N. Shoutko, O. A. Gerasimova, L. P. Ekimova, F. K. Zherebtsov V. F. Mus, D. A. Granov, and A. M. Granov, Long term activation of circulating liver-committed mononuclear cells after OLT, J J Regener Med, vol. 1 (3), pp.011, March 2016. http://regenerativemedicine.jacobspublishers.com/images/Regena rative/J_J_Regener_Med_1_3_011.pdf.

[4] A. Shoutko, L. Ekimova, V. Mus, and V. Sokurenko, Fluctuations of CD34 cells number in blood of cancer patients during final year of life, Medical and Health Science Journal (MHSJ), 2012. vol.13 (4), pp.7-13, January 2012. doi: http://dx.doi.org/10.15208/mhsj.2012.52.

[5] B.-S. Ding, D. James, R. Iyer, I. Falciatori, D. Hambardzumyan, Su Wang, J. M. Butler, S. Y. Rabbany, and A.Hormigo, Prominin 1/CD133 endothelium sustains growth of proneural glioma, PloS ONE, vol. 8 (4), pp. e62150, April 2013. doi:10.1371/journal.pone.0062150.

[6] I. Colmegna, A. Diaz-Borjon, H. Fujii, L. Schaefer, J. J. Goronzy, and $\mathrm{C}$ M. Weyand, Defective proliferative capacity and accelerated telomeric loss of hematopoietic progenitor cells in rheumatoid arthritis, Arthritis Rheum, vol. 58 (4),pp. 990-1000. April 2008. doi: 10.1002/art.23287.

[7] G. Van Zant, and Ying Liang, Concise Review: Hematopoietic stem cell aging, life span, and transplantation, Stem Cells Transplantational Medicine, vol.1 (9), pp. 651-657, September 2012.doi:10 5966/sctm.2012-0033.

[8] H. Silva, and I. M. Conboy, Aging and stem cell renewal, in: Stem Book,internet, L. Girard, Ed., Harvard Stem Cell Institute, Harvard University, July, 2008. PMID: 20614587: doi: 10.3824/stembook.1.11.1 doi/10.3824/stembook.1.11.1,

[9] A. N. Shoutko, and L. P. Ekimova. The impact of middle age on the viability of patients with nonmalignant and malignant diseases. Cancer Research Journal, vol. 2 (6), pp. 114-120, December 2014. doi: 10.11648/j.crj.20140206.14 10.

[10] L. Chen, Y. Lou, Y. Chen, and J. Yang, Prognostic value of the neutrophil-to-lymphocyte ratio inpatients with acute-on-chronic liver failure, Int J Clin Pract, 68 (8), pp. 1034-1040, August 2014. doi: $10.1111 /$ ijcp.12408.

[11] A. M. Granov, D. A. Granov, F. K. Zherebtsov, O. A. Gerasimova, V. V. Borovik, V. V. Osovskikh, D. N. Maystrenko, I. O. Rutkin, S. P. Tsurupa, I. I. Tileubergenov, S. V. Shapoval, and T. G. Mikhaylichenko, Livertransplantation. A single center experience of 100 cases, Vestnik transplantologii I iskusstvennich organov, vol. 14 (4), pp.11-16, December 2012 journal.transpl.ru〉.

[12] Curve fitting project - pdf.io, pp. 1-4. dynsys.uml.edu/tutorials/Regression.../curve_fit_proj_101905. pdf.

[13] Sh. S. Eaker, T. S. Hawley, A. Ramezani, and R. G. Hawley, Detection and enrichment of hematopoietic stem cells by side population phenotype, in: Methods in molecular biology: flow cytometry protocols, 2nd ed., T. S. Hawley and R. G. Hawley Eds., (C) Humana Press Inc., Totowa, NJ, 2004, pp161-180. https://flowcytometry.gwu.edu/.../flowcytometry.../fcp9.pdf.

[14] I. Sales-Pardo, A. Avendaño, V. Martinez-Muñoz, M. GarcíaEscarp, R. Celis, Ph. Whittle, J. Barquinero, J. C. Domingo, P. Marin, and J. Petriz, Flow cytometry of the side population: tips\& tricks, Cellular oncology, vol. 28 (1-2), pp. 37-53, January 2006. http://dx.doi.org/10.1155/2006/536519.

[15] St. L. Nelson, Statistical formulas in Excel. stephenlnelson.com/articles/statistical-formulas-in-excel/.

[16] J. L. Loveland,. Mathematical justification of introductory hypothesis tests and development of reference Materials, (report for M. Sc. "Mathematics"). Utah State University, 2011, Retrieved April/2013. digitalcommons.usu.edu>... GRADREPORTS $>14$.

[17] A. Medkhaly, E. Simoneau, S. Doi, P. Metrakos, and M. Hassanain, Developing a prognostic score for early prediction of graft and patient survival after orthotopic liver transplantation Am J Transplant, 2013; $13 \quad$ (suppl 5). http://www.atcmeetingabstracts.com/abstract/developing-aprognostic-score-for-early-prediction-of-graft-and-patientsurvival-after-orthotopic-liver-transplantation/.

[18] Lee S-G, Hwang Sh, LeeY-J, Park K-M, Jeon H-B, Min PCh. Regeneration of graft liver in adult-to-adult living donor liver transplantation using a left lobe graft. J. Korean Med. Sci. vol. 13 (4), pp. 350-354, August 1998. https://uic.pure.elsevier.com/.../regeneration-of-graft-liver-in.

[19] A. Jain, J. Reyes, R. Kashyap, S. F. Dodson, A. J. Demetris, K. Ruppert, K. Abu-Elmagd, W. Marsh, J. Madariaga, G. Mazariegos, D. Geller, C. A. Bonham, T. Gayowski, T. Cacciarelli, P. Fontes, T. E. Starzl, and J. J. Fung, Long-term survival after liver transplantation in 4,000 consecutive patients at single center, Ann Surg, vol. 232 (4), pp. 490-500 October 2000. PMC1421181.

[20] A. Ekka-Zochar, Y. Zitser-Gurevich, M. Mandel, I. Weiss-Salz, S. Nir, E. Mor, N. Richard, H. Merhav, R. Bruck, and E. Simchen, Graft survival and its determinants: a 3 year national experience with liver transplantation in Israel. IMAJ, vol.8 (6), pp.400-405, Dec. 2006. PMID: 16833169.

[21] Zhong Li, CD133: a stem cell biomarker and beyond, Exp Hematol Oncol, 2 (17) July 2013.doi: 10.1186/2162-3619-2-17.

[22] P. G. Bertolino, W. D. Mc Caughan, and G. Bowen, Role of primary intrahepatic T-cell activation in the 'liver tolerance effect', Immunology and Cell Biology, vol.80, pp.4-92, October2002. doi:10.1046/j.0818-9641.2001.01048.x. 
[23] R. Turner, O. Lozoya, Y. Wang, V. Cardinale, E. Gaudio, G. Alpini, G. Mendel, E. Wauthier, C. Barbier, D. Alvaro, and L. M. Reid, Human hepatic stem cell and maturation liver lineage biology, Hepatology, vol. 53 (3), pp.1035-1045, March 2011. PMID: 21374667, doi: 10.1002/hep.24157.

[24] Y. Haruna, K. Saito, S. Spaulding, M. A. Nalesnik, and M. A. Gerber, Identification of bipotential progenitor cells in human liver development, Hepatology, vol. 23 (3), pp. 476-481, March 1996. PMID: 8617427, doi: 10.1002/hep.510230312.

[25] O. D. Liang, T. Korff, J. Eckhardt, J. Rifaat, N. Baal, F. Herr, K. T. Preissner, and M. Zygmunt, Oncodevelopmental alphafetoprotein acts as a selective proangiogenic factor on endothelial cell from the fetomaternal unit. J Clin Endocrinol Metab, vol.89 (3), pp. 1415-22, March 2004. doi: https://doi.org/10.1210/jc.2003-031721.

[26] S. Schwartzenberg, A. Mor, G. Luboshits, D. Planer, V. G. Deutsch, G. Keren, and J. Georgeet, Association between circulating early endothelial progenitors and CD4+CD25+regulatory T-cells: a possible cross-talk between immunity and angiogenesis? Am J Immunol, vol.1 (4), pp. 143147, 2005. thescipub.com/html/10.3844/ajisp.2005.143.147.

[27] M. Romano, F. De Francesco, G. Pirozzi, E. Gringeri, R. Boetto, M. Di Domenico, B. Zavan, G A. Ferraro, and U. Cillo, Expression of cancer stem cell biomarkers as a tool for a correct therapeutic approach to hepatocellular carcinoma, Oncoscience, vol. 2 (5) pp. 443-456, doi: 10.18632/oncoscience.163, PMC4468330.

[28] J. Hur, H.-M. Yang, Ch.-H. Yoon, Ch.-S. Lee, K.-W. Park, J.-H. Kim, T.-Y. Kim, J.-Y. Kim, H.-J. Kang, I.-H. Chae, B.-H. Oh, Y.B. Park, and H.-S. Kim, Identification of a novel role of T-cells in postnatal vasculogenesis, Circulation, vol.116 (15) pp. 16711682, October $2007 . \quad$ PDF https://doi.org/10.1161/CIRCULATIONAHA.107.694778.

[29] Wenbo Meng, Xun Li, Zhongtian Bai, Yan Li, Jinqiu Yuan, Tao Liu, Jun Yan, Wence Zhou, Kexiang Zhu, Hui Zhang, and Yumin $\mathrm{Li}$, Silencing alpha-fetoprotein inhibits VEGF and MMP-2/9 production in human hepatocellular carcinoma cell. PLoS ONE, 9 (2), pp. e90660, February 2014. http://dx.doi.org/10.1371/journal.pone.0090660.

[30] E. Arias, United States Life Tables, 2006, in: National vital statistics reports from U.S. Department of health and human services centers for disease control and prevention, National center for health statistics, National vital Statistics System, vol. 58 (21), pp.1-40, June 2010.

https://www.cdc.gov/nchs/data/nvsr/nvsr58/nvsr58_21.pdf.

[31] K. Billups, J. Neal, and J. Salyer, Immunosuppressant-driven de novo malignant neoplasms after solid-organ transplant, Progress in Transplantation, vol. 25 (2), pp. 182-188, June 2015. doi: http://dx.doi.org/10.7182/pit2015826.

[32] Karynsa Cetin, David S Ettinger, Yong-jiang Hei, and C. D. O'Malley, Survival by histologic subtype in stage IV nonsmall cell lung cancer based on data from the Surveillance, Epidemiology and End Results, Program Clinical Epidemiology, vol. 3, pp.139-148, April 2011. DOI: 10.2147/CLEP.S17191.

[33] 32 J. Baba, S. Watanabe, Y. Saida, T. Tanaka, T. Miyabayash, J. Koshio, K. Ichikawa, K. Nozaki, T. Koya, K. Deguchi, C. Tan, S. Miura, H. Tanaka, J. Tanaka, H. Kagamu, H.Yoshizawa, K. Nakata, and I. Narita, Depletion of radio-resistant regulatory T cells enhances antitumor immunity during recovery from lymphocytopenia, Blood, vol.120 (12),pp.2417-2427 July 2012.
PMID: 22806892 doi: 10.1182/blood-2012-02-411124.

[34] U.S. Department of health and human services, National institute of health, National cancer Institute,"Blood/bone marrow," in: Common terminology criteria for adverse events (CTCAE)/Version 3.0, AMGEN Oncology, p.4, August 2006. ctep.cancer.gov/.../electronic.../ctcaev3.pdf.

[35] K. S. Tewari, J. J. Java, T. A. Gatcliffe, M. A. Bookman, and B. J. Monk, Chemotherapy-induced neutropenia as a biomarker of survival in advanced ovarian carcinoma: an exploratory study of the gynecologic oncology group, Gynecol Oncol, vol.133 (3), pp.439-445. March 2014. doi: 10.1016/j.ygyno.2014.03.013.

[36] Z. Su, Y.-P. Mao, P.-Y. Ou Yang, J. Tang, X.-W. Lan, and F.-Y. Xie, Leucopenia and treatment efficacy in advanced nasopharyngeal carcinoma, BMC Cancer, vol.15, pp. 429. May 2015. doi:10.1186/s12885-015-1442-3.

[37] A. Shoutko, L. Yurkova, K. Borodulya, and L. Ekimova, Lymphocytopenia and cytotoxic therapy in patients with advanced ovarian cancer, Cancer Research J, 3 (3), pp. 47-51, May 2015. doi:10.11648/j.crj.20150303.11.

[38] W. W. Pang, E. A. Price, D. Sahoo, I. Beerman, W. J. Maloney, D. J. Rossi, S. L. Schrier, and I. L. Weissman, Human bone marrow hematopoietic stem cells are increased in frequency and myeloidbiased with age, PNAS USA, vol.108, pp.20012-20017, June 2011. doi: 10.1073/pnas.1116110108.

[39] A. N. Shoutko, and L. P. Ekimova Lymphocytopenia can contribute in common benefit of cytotoxic therapy of cancer, "Inter-Medical", vol.3,pp. 5-13, 2014. www.intermedical.ru/.../78-lymphocytopenia-can-contribute-in-common-.

[40] A. Shoutko, L. Yurkova, K. Borodulya, and L. Ekimova, Protracted half-body irradiation instead of chemotherapy: life span and lymphocytopenia in relapsed ovarian cancer, Int $\mathrm{J}$ of Tumor Therapy, 5 (1), pp.1-7, Feb 2016. doi: 10.5923/j.jitt.20160501.01.

[41] A. N. Shoutko, and L. P. Ekimova Abnormal tissue proliferation and life span variability in chronically irradiated dogs, Radiat Environ Biophys, vol.53 (1), pp.65-72, March 2014. PMID: 24310526: doi: 10.1007/s00411-013-0504-7.

[42] A. D. Hayward, I. Nenko, and V. Lummaa, Early-life reproduction is associated with increased mortality risk but enhanced lifetime fitness in pre-industrial humans Proc. R. Soc. B: Biological Sciencesss, vol.282(1804), pp. 20143053. March 2015. doi: 10.1098/rspb.2014.3053; http://dx.doi.org/10.1098/rspb.2014.3053.

[43] WHO Recommendations for prevention and treatment of preeclampsia and eclampsia. Geneva: World Health Organization, Background 1, Bookshelf ID: NBK1405632011, National Center for Biotechnology Information, U.S. National Library of Medicine 8600 Rockville Pike, Bethesda MD, 20894 USA. https://www.ncbi.nlm.nih.gov/books/NBK140563/.

[44] P, Luppi, R. W. Powers, V. Verma, L. Edmunds, D. Plymire, and C. A. Hubel, Maternal circulating CD34+VEGFR-2+ and CD133+ VEGFR-2+ progenitor cells increase during normal pregnancy but are reduced in women with preeclampsia, Reprod Sci, vol. 17 (7), pp. 643-652, July 2010. doi: 10.1177/1933719110366164, www.ncbi.nlm.nih.gov/pmc/...; PMC2893245. 